\title{
Conjunction errors and semantic transparency
}

\author{
Mungchen Wong and Caren M. Rotello \\ University of Massachusetts, Amherst, Massachusetts
}

\begin{abstract}
Memory conjunction errors occur when aspects of two different events are falsely recognized or recalled as having occurred as parts of the same event. One theoretical account of conjunction errors is rooted in traditional dual-process models of recognition judgments, in which responses are based on an item's familiarity or the retrieval of recollected details associated with the encoding of that item. We manipulated the familiarity of test probes by varying their semantic overlap with studied items, taking advantage of the inherent semantic transparency of compound words. Transparent compounds are those whose component parts (lexemes) are semantically related to the meaning of the entire word. In contrast, opaque compounds' lexemes do not contribute directly to the meaning of the compound. We showed that the familiarity of semantically transparent assembly lures created from their lexemes (study dog and house, test on doghouse) is greater than the familiarity of opaque assembly lures (study back and draw, test on drawback). A response-signal experiment revealed no evidence for the use of a recall-to-reject process for either semantically transparent or opaque lures.
\end{abstract}

Imagine learning that drinking wine reduces the risk of diabetes and that drinking coffee decreases cholesterol levels. Later, you nod in understanding when a friend tells you that she's avoiding coffee to reduce her risk of diabetes. Memory conjunction errors like this one occur quite frequently, and they are typically not experienced as errors. Given that people are usually unaware of their memory conjunction errors, understanding them is of obvious practical and theoretical significance. How do those false memories arise?

In the memory conjunction paradigm, participants study a series of items (e.g., compound words) and then take a recognition test. Conjunction lures are usually generated by combining features of two studied parent items (blackmail, jailbird) to create a new item (blackbird). Likewise, feature lures are made by combining a feature from one studied parent with a feature from a new item (blackboard); new lures are composed of two novel features (shotgun). Conjunction errors occur when the participants falsely identify conjunction lures as previously studied items; feature errors are false alarms to feature lures.

The dominant explanation for memory conjunction errors is based on theories of recognition memory that assume that subjectively familiar memory probes are more likely to be called old. Conjunction lures are similar to two previously studied items, so they feel familiar and are likely to elicit false alarms (Jones, 2005; Jones \& Atchley, 2002; Jones \& Jacoby, 2001; Lampinen, Odegard, \& Neuschatz, 2004). Feature lures are similar to only one studied item and yield fewer errors. New lures are not similar to any studied items and elicit the lowest error rate.

According to dual-process theories of recognition memory, judgments can be based on an item's familiarity or on the results of a recollective process (see Yonelinas, 2002 , for a review). For a studied item, recollection of episodic details can support a probe's familiarity via a recallto-accept process. In contrast, for both conjunction lures and feature lures, recollection of a parent item provides evidence that the lure was not studied; this process has been termed recall-to-reject (e.g., Rotello \& Heit, 1999). In principle, false recognition of conjunction and feature lures could be reduced with a recall-to-reject process. Indeed, some studies have shown that the use of recall-toreject reduces the conjunction error rate (e.g., Lampinen et al., 2004), especially with very short lags between the presentations of the parent and the lure (Jones \& Atchley, 2006). Overall, however, it is apparent that either a recall-to-reject strategy is not used by the majority of participants facing conjunction lures or it is used quite ineffectively, because the conjunction error rate is substantial in most studies.

Participants face the challenge of identifying the source of the familiarity of the conjunction lure, which varies with its orthographic/phonemic and conceptual overlap with the studied items. Errors are higher when the conjunction lures are created from lexical morphemes, or lexemes, of compound words rather than nonmorphemic syllables (Jones, Brown, \& Atchley, 2007). That is, false alarms are higher to crossbow after studying crossroad and rainbow than to custom after studying custard and phantom. One possible explanation is that the lexically based lures are more semantically related to the parents than are the syllable-based lures. Ghatala, Levin, Bell, Truman, and Lodico (1978) found a higher error rate to conjunction lures when their participants were urged toward an interpretation of the lexemes that was consistent

C. M. Rotello, caren@psych.umass.edu 
with the meaning in the conjunction. For example, participants who studied [soft]bed and [cloth]spread made more errors to bedspread than did participants who studied [river]bed and [cheese]spread. In a related study, Jones and Atchley (2006) found that the probability of a conjunction error was predicted by the associative strength from the first lexeme either to the second lexeme or to the compound. The degree of semantic overlap between one or more of the studied parent compounds (wildfire, nightlife or businessmeeting, chairman) and the associated lures (low overlap, wildlife; high overlap, businessman) also influences the false alarm rate to conjunction and feature lures (Leding, Lampinen, Edwards, \& Odegard, 2007; Odegard, Lampinen, \& Toglia, 2005).

Our goals were to evaluate the familiarity-based account of memory conjunction errors and to assess the use of a recall-to-reject process in these judgments. We manipulated the semantic overlap of the studied items and their lures by varying their semantic transparency, on the assumption that both familiarity-based responding and use of recall-to-reject would be enhanced by greater semantic overlap. Transparent compound words are those for which both lexemes contribute to the overall meaning of the word; opaque compound words are those for which the lexemes do not contribute to the meaning of the word (e.g., Jarema, Busson, Niklova, Tsapkini, \& Libben, 1999). For example, doghouse is transparent, because the compound is semantically related to both lexemes (i.e., doghouse literally means a house for a dog). In contrast, blackmail is opaque, because the compound is semantically and conceptually unrelated to the lexemes (i.e., blackmail has little relation to either black or mail).

Semantic transparency is defined by the semantic overlap of the compound words and their lexemes; therefore, it is related, but not identical, to the semantic overlap shared by sets of compound words (Leding et al., 2007; Odegard et al., 2005). For example, candlestick is semantically transparent regardless of whether it occurs in a low (slapstick) or high (candlewax) overlap context; shortbread is semantically opaque in both low (shortcoming) and higher (flatbread) overlap contexts. Whereas semantic overlap is relevant in most studies of conjunction error rates, in which conjunction lures are created by rearranging the lexemes of two studied parent words, in the present experiments we focused on the semantic relationship between the lexemes and the compound. As we will describe in detail later, we extended the design of Jones et al. (2007, Experiment 3) to include semantic transparency: Participants were tested on the lexemes of studied compounds that varied in their transparency, and both transparent and opaque compound lures were created by combining individually studied lexemes.

We predicted that semantic transparency would affect the memory activation and perceived familiarity of compounds and lexemes. If the familiarity-based account of memory conjunction errors is correct, the transparency of the studied compounds should influence conjunction error rates. We evaluated this hypothesis in Experiment 1. Semantic transparency should also influence recollection, since greater semantic overlap would provide a better retrieval cue for the studied item. In Experiment 2, we evaluated the role of recall-to-reject processing using a response-signal paradigm. We begin, however, by describing a norming study on the compound word pool from which we drew our items.

\section{STIMULUS NORMING}

\section{Method}

Participants. Forty University of Massachusetts undergraduates participated for extra credit in their psychology courses. All of them were native speakers of English.

Procedure. The participants saw 80 compound words, 1 at a time. All 80 of these stimuli appear as unhyphenated single words in the online Merriam-Webster dictionary (www.merriam-webster .com). For each word, the participants gave a transparency rating on a 7 -point scale $(1$, the word is very opaque; 7 , the word is very transparent), and then they judged its familiarity and concreteness, also on 7-point scales. Transparency was described as the degree of semantic relationship between the two lexemes of the compound and the whole word; examples were provided for both transparent and opaque compounds.

\section{Results}

We defined transparent compounds as those with an average transparency rating greater than $4.50(M=6.10$, $S D=0.41)$. Opaque compounds had ratings lower than $4.50(M=2.70, S D=0.76)$. Transparent and opaque compounds also differed significantly in their mean familiarity ratings (opaque, $M=5.17, S D=1.13$; transparent, $M=6.34, S D=0.56)[t(39)=5.25, p<.001$, Cohen's $d=.83$ ] and in their mean concreteness ratings (opaque, $M=4.06, S D=1.72$; transparent, $M=6.14$, $S D=0.52)[t(39)=7.30, p<.001, d=1.15]$.

\section{EXPERIMENT 1}

In Experiment 1, we examined the role of semantic transparency in memory error rates. A study list of short singletons (e.g., tooth), long singletons (e.g., secretary), and compound words (e.g., beeline) was created. Two types of critical lures were created. Disassembly lures were individual lexemes of studied compound words, tested separately (e.g., study doghouse, test on dog and house). More false alarms were expected to disassembly lures from transparent compounds than to those from opaque compounds. Assembly lures were compound words created from studied lexemes (e.g., study draw and back, test on drawback). We predicted that transparent assembly lures would elicit more errors than would opaque assembly lures. Our predictions are focused on these error rates, since there is no reason to think that the transparency of a studied compound would influence the probability that it would be correctly recognized (transparent compounds do not share any more semantic features with themselves than do opaque compounds). Similarly, error rates to completely new lures, those unrelated to any studied items, would not be expected to vary with semantic transparency.

\section{Method}

Participants. Forty-four University of Massachusetts undergraduates participated for extra credit in their psychology courses. 
Table 1

Design of Experiment 1, With Example Stimuli

\begin{tabular}{|c|c|c|c|c|c|c|}
\hline \multicolumn{3}{|c|}{ Study Phase } & \multicolumn{4}{|c|}{ Test Phase } \\
\hline Item Type & Number & Example & Item Type & Number & Example & Test Status \\
\hline Compound word & $\begin{array}{l}10 \text { opaque } \\
10 \text { transparent }\end{array}$ & $\begin{array}{l}\text { beeline } \\
\text { bedroom }\end{array}$ & Compound word & $\begin{array}{l}10 \text { opaque } \\
10 \text { transparent }\end{array}$ & $\begin{array}{l}\text { beeline } \\
\text { bedroom }\end{array}$ & Compound target \\
\hline Critical compound word & $\begin{array}{l}5 \text { opaque } \\
5 \text { transparent }\end{array}$ & $\begin{array}{l}\text { scapegoat } \\
\text { toothpick }\end{array}$ & Lexeme & $\begin{array}{l}10 \text { opaque } \\
10 \text { transparent }\end{array}$ & $\begin{array}{l}\text { scape, goat } \\
\text { tooth, pick }\end{array}$ & Disassembly lure $^{\dagger}$ \\
\hline Lexeme & $\begin{array}{l}10 \text { opaque } \\
10 \text { transparent }\end{array}$ & $\begin{array}{l}\text { tread, mill } \\
\text { flag, pole }\end{array}$ & Lexeme & $\begin{array}{l}10 \text { opaque } \\
10 \text { transparent }\end{array}$ & $\begin{array}{l}\text { tread, mill } \\
\text { flag, pole }\end{array}$ & Singleton target \\
\hline Lexeme & $\begin{array}{l}10 \text { opaque } \\
10 \text { transparent }\end{array}$ & $\begin{array}{l}\text { wall, flower } \\
\text { cheek, bone }\end{array}$ & Compound word & $\begin{array}{l}5 \text { opaque } \\
5 \text { transparent }\end{array}$ & $\begin{array}{l}\text { wallflower } \\
\text { cheekbone }\end{array}$ & Assembly lure $^{\dagger}$ \\
\hline \multirow[t]{3}{*}{ Filler } & $\begin{array}{l}20 \text { long } \\
10 \text { short }\end{array}$ & $\begin{array}{l}\text { secretary } \\
\text { beer }\end{array}$ & & & & \\
\hline & & & Compound word & $\begin{array}{l}10 \text { opaque } \\
10 \text { transparent }\end{array}$ & $\begin{array}{l}\text { shortbread } \\
\text { fingertip }\end{array}$ & Compound lure \\
\hline & & & Lexeme & $\begin{array}{l}10 \text { opaque } \\
10 \text { transparent }\end{array}$ & $\begin{array}{l}\text { straw, berry } \\
\text { wheel, chair }\end{array}$ & Singleton lure \\
\hline
\end{tabular}

$\dagger$ Critical item type.

All were native English speakers, and none had participated in the norming study.

Stimuli and Design. The stimulus structure for Experiment 1 is shown in Table 1, along with example stimuli of each type. There were 80 compound words, half opaque (mean transparency $=2.72$ ) and half transparent (mean transparency $=6.06$; see the Appendix); compounds were randomly assigned to conditions for each participant. Twenty compounds (half opaque) were studied and tested as compounds (compound targets); an additional 20 (half opaque) served as compound lures on the test. Ten compounds (half opaque) were studied as compounds but split into their component lexemes (disassembly lures) at test. Ten compounds (half opaque) were broken into their component lexemes for the study phase but were tested as compound words (assembly lures). Ten compounds (half opaque) were broken into their component lexemes both at study and at test; for clarity, we will call these singleton targets. The remaining 10 compounds (half opaque) were not studied but were broken into their component lexemes and appeared as singleton lures on the test. Although the notion of transparency is irrelevant for the singletons, we nonetheless treated those taken from opaque and transparent compounds differently in the data summary (and in Table 1). Doing so allowed us to evaluate whether any uncontrolled differences in the stimuli (e.g., letter bigram frequency) influenced the memory judgments.

The opaque and transparent compounds were matched on mean number of letters (opaque, $M=8.9$; transparent, $M=8.6$ ), number of syllables (opaque, $M=2.1$; transparent, $M=2.2$ ), and, to the extent possible, Kučera-Francis (1967) frequency (opaque, $M=$ 10.3; transparent, $M=9.0$; although most of the compounds were not listed in the norms). The lexemes of the compounds were also matched on mean number of letters $(M=4.3$ for those with opaque parents, $M=4.5$ for those with transparent parents), number of syllables (opaque parents, $M=1.1$; transparent parents, $M=1.1$ ), and Kučera-Francis frequency (opaque,${ }^{1} M=98.0$; transparent, $M=$ 73.9) $[t(137)=1.09, p>.25, d=.18]$. Equating the compounds on the linguistic frequency of their component lexemes is particularly important, because lexical decision times, naming times, and patterns of eye movements in the reading of compound words all vary with the frequency of the lexemes (e.g., Juhasz, Starr, Inhoff, \& Placke, 2003).

There were also 34 singletons that appeared only at study and on the practice test. Fourteen singletons were one-syllable short words (mean length $=4.7$ letters); 20 were long words with three or four syllables (e.g., secretary). The long singletons were matched with the compound words in terms of number of letters $(M=8.7)$ and part of speech.
Altogether, the study list contained 100 items: 30 compound words (half opaque), 40 lexemes of compound words (half with opaque parents), and 20 long and 10 short filler words. The order of the study items was randomized for each participant. Four additional short filler words were used as primacy and recency buffer items.

The test list contained 110 test items, shown schematically in Table 1 . There were 50 compound words ( 20 targets, 20 lures, and 10 assembly lures) and 60 singletons (20 targets, 20 lures, and 20 disassembly lures). Within each class of test item, half of the probes were opaque or had opaque parents; the others were transparent or had transparent parents. Test order was randomized for each participant.

Procedure. The participants studied a list of words one at a time, centered on a computer screen, for 2,000 msec each with an interstimulus interval of $1,000 \mathrm{msec}$; they were asked to learn the words for an upcoming recognition test. After viewing the study list, the participants were given a 10 -word practice test composed of filler words, followed by the 110-item test list. For each test probe, the participants made an unspeeded old-new recognition judgment, followed by a confidence rating $(1$, sure new; 6 , sure old $)$. Because we did not want to influence the participants' encoding of the compound words and their lexemes, the participants were not told that there would be assembly or disassembly lures on the test.

\section{Results}

The mean proportion of old responses to each stimulus class is shown in Table 2. As was expected, old-new recognition accuracy did not differ with semantic transparency: The probability of an old response was greater for targets $(M=0.70, S D=0.18)$ than for lures $(M=0.23$, $S D=0.15)[t(43)=15.54, p<.01, d=2.34]$ and did not vary with transparency $\left(F_{\mathrm{S}}<1\right)$. In contrast, the false alarm rates to the assembly and disassembly lures were both greater for transparent words than for opaque words [disassembly lures, $F(1,43)=9.17, M S_{\mathrm{e}}=0.03, p<.01$, Cohen's $f=0.46$; assembly lures, $F(1,43)=4.75, M S_{\mathrm{e}}=$ $0.06, p<.05, f=0.33] .^{2}$ Moreover, the false alarm rate to transparent, but not opaque, disassembly lures was significantly greater than the false alarm rate to singleton lures [transparent disassembly lures, $M=0.32$, transparent singleton lures, $M=0.23, t(43)=3.50, p<.01, d=$ .53 ; opaque dissassembly lures, $M=0.23$, opaque singleton lures, $M=0.22, t(43)<1, d=.13$ ]. 
Table 2

Proportion of Old Responses and $S D$ s to Each Stimulus Type in Experiment 1

\begin{tabular}{|c|c|c|c|c|c|c|c|c|c|c|c|c|}
\hline \multirow{3}{*}{$\begin{array}{l}\text { Semantic } \\
\text { Transparency }\end{array}$} & \multicolumn{6}{|c|}{ Singletons } & \multicolumn{6}{|c|}{ Compound Words } \\
\hline & \multicolumn{2}{|c|}{ Targets } & \multicolumn{2}{|c|}{ Lures } & \multicolumn{2}{|c|}{$\begin{array}{l}\text { Disassembly } \\
\text { Lures }\end{array}$} & \multicolumn{2}{|c|}{ Targets } & \multicolumn{2}{|c|}{ Lures } & \multicolumn{2}{|c|}{$\begin{array}{l}\text { Assembly } \\
\text { Lures }\end{array}$} \\
\hline & $M$ & $\overline{S D}$ & $M$ & $\overline{S D}$ & $M$ & $\overline{S D}$ & $M$ & $\overline{S D}$ & $M$ & $\overline{S D}$ & $M$ & $\overline{S D}$ \\
\hline Opaque & 0.66 & 0.20 & 0.22 & 0.17 & $0.23^{*}$ & 0.18 & 0.75 & 0.17 & 0.17 & 0.17 & $0.23^{* *}$ & 0.23 \\
\hline Transparent & 0.66 & 0.22 & 0.23 & 0.18 & $0.32^{*}$ & 0.22 & 0.72 & 0.20 & 0.16 & 0.15 & $0.31^{* *}$ & 0.24 \\
\hline
\end{tabular}

The nominal difference in the linguistic frequencies of the component lexemes cannot account for the observed differences in false alarm rates to disassembly lures: In general, lower frequency words yield a lower false alarm rate (e.g., Glanzer \& Adams, 1990; Wixted, 1992), whereas the lexemes of our transparent (and nominally lower frequency) compounds elicited more false alarms. No other stimulus difference appears to account for our data either. A correlational analysis across the stimuli revealed that the disassembly error rate was significantly correlated with the transparency of the parents $(r=.38$, $\left.n=60 ; \chi^{2}=8.98, p=.003, \phi=.39\right)$, but not with either familiarity $(r=.08)$ or concreteness $(r=.04)$. (We did not run a parallel analysis on the responses to assembly lures, because they were created from studied lexemes, for which we do not have transparency, familiarity, or concreteness ratings.)

Transparent disassembly lures were recognized with higher confidence $(M=2.83, S D=0.78)$ than were opaque disassembly lures $(M=2.59, S D=0.67)[t(43)=$ $2.80, p<.01, d=.42]$. Relative to singleton lures $(M=$ $2.55, S D=0.59)$, transparent disassembly lures were recognized with higher confidence $[t(43)=4.03, p<.001$, $d=0.61]$, but opaque disassembly lures were not: $[t(43)=$ $0.54, p=.59, d=0.08]$. Similarly, the mean confidence rating for transparent assembly lures $(M=2.69, S D=0.91)$ was greater than that for opaque assembly lures $(M=2.45$, $S D=0.90)[t(43)=1.73, p<.05, d=.26]$. Both transparent and opaque assembly lures were recognized with higher confidence than were new compound lures $(M=$ $2.20, S D=0.58)$ [transparent, $t(43)=4.79, p<.001, d=$ .72 ; opaque, $t(43)=2.46, p=.018, d=.37]$.

Finally, because the use of recall-to-reject would influence the probability that a lure is confidently rejected (Rotello, Macmillan, \& Van Tassel, 2000), we evaluated whether transparent assembly or disassembly lures were labeled sure new more often than opaque assembly or disassembly lures. They were not. The probability that assembly lures were rejected with the highest confidence did not differ with semantic transparency (opaque, $M=$ .26 ; transparent, $M=.24)[t(43)<1, d=.07]$, nor did the probability that disassembly lures were rejected with the highest confidence (opaque, $M=.38$; transparent, $M=$ .35) $[t(43)=1.20, p>.20, d=.18]$.

\section{Discussion}

Our primary result was that semantic transparency affected the false alarm rate to lexemes of studied compounds (disassembly lures) and to unstudied compounds constructed from studied lexemes (assembly lures). This finding may explain some of the variability of false alarm rates to feature lures (Jones \& Jacoby, 2001), which are composed of one studied lexeme and one novel lexeme: If the studied lexeme is part of a transparent compound, the expected feature error rate will be higher than if the studied lexeme has an opaque parent. Therefore, studies in which the majority of studied compounds are semantically transparent are likely to yield higher feature error rates than studies in which the compounds are primarily opaque; in the latter case, the feature error rate would be near the false alarm rate to completely novel compounds.

The finding that assembly lures were judged old more often than novel compounds is surprising, given that all study items were randomly distributed in the study list. That is, even though house could be presented early in the study list, and $d o g$ might not occur until much later, the participants were still more likely to respond with a false alarm to the assembly lure doghouse than to a new compound word that was not previously studied (see also Jones et al., 2007, Experiment 3). Assembly errors also showed an effect of transparency: Transparent assembly lures elicited false alarms more often and with greater confidence than opaque assembly lures.

The lexemes of opaque compounds yielded very low false alarm rates, which did not differ from the false alarms to completely novel lexemes, a result with several possible causes. Opaque features may have been treated as if they were new because they did not seem familiar, or they may have felt familiar but were nonetheless rejected with a recall-to-reject process. We find the second explanation implausible, because the rate of highly confident correct rejections did not differ with semantic transparency; thus, there is no evidence that the use of recall-to-reject processing varied with transparency. Nonetheless, we tested this hypothesis directly in Experiment 2. A third explanation for the results of Experiment 1 is that the lexemes of transparent and opaque compounds, as well as the compounds themselves, vary both in relative familiarity and in how easy they are to recollect. Opaque compounds, but not their lexemes, might be easy to recollect, whereas both transparent compounds and their lexemes might be easy to recall. Thus, familiarity-based processing and recall-toreject may trade off in complex ways.

\section{EXPERIMENT 2}

In Experiment 2, we examined the role of recall-toreject in the judgments of disassembly lures using a 
Table 3

Design of Experiment 2, With Example Stimuli

\begin{tabular}{|c|c|c|c|c|c|c|}
\hline \multicolumn{3}{|c|}{ Study Phase } & \multicolumn{4}{|c|}{ Test Phase } \\
\hline Item Type & Number & Example & Item Type & Number & Example & Test Status \\
\hline Compound word & $\begin{array}{l}10 \text { opaque } \\
10 \text { transparent }\end{array}$ & $\begin{array}{l}\text { beeline } \\
\text { bloodstain }\end{array}$ & Compound word & $\begin{array}{l}10 \text { opaque } \\
10 \text { transparent }\end{array}$ & $\begin{array}{l}\text { beeline } \\
\text { bloodstain }\end{array}$ & Compound target \\
\hline Critical compound word & $\begin{array}{l}10 \text { opaque } \\
10 \text { transparent }\end{array}$ & $\begin{array}{l}\text { sidekick } \\
\text { cheekbone }\end{array}$ & Lexeme & $\begin{array}{l}20 \text { opaque } \\
20 \text { transparent }\end{array}$ & $\begin{array}{l}\text { side, kick } \\
\text { cheek, bone }\end{array}$ & Disassembly lure $^{\dagger}$ \\
\hline \multirow[t]{3}{*}{ Filler } & $\begin{array}{l}30 \text { short } \\
30 \text { long }\end{array}$ & $\begin{array}{l}\text { beer } \\
\text { umbrella }\end{array}$ & Filler & $\begin{array}{l}20 \text { short } \\
20 \text { long }\end{array}$ & $\begin{array}{l}\text { beer } \\
\text { umbrella }\end{array}$ & Filler target \\
\hline & & & Compound word & $\begin{array}{l}10 \text { opaque } \\
10 \text { transparent }\end{array}$ & $\begin{array}{l}\text { wallflower } \\
\text { flagpole }\end{array}$ & Compound lure \\
\hline & & & Filler & $\begin{array}{l}20 \text { short } \\
20 \text { long }\end{array}$ & $\begin{array}{l}\text { milk } \\
\text { mosquito }\end{array}$ & Filler lure \\
\hline
\end{tabular}

†ritical item type.

response-signal paradigm. Because the lexemes of studied transparent compounds apparently feel familiar, errors to transparent disassembly lures are expected to occur readily at short response-signal lags when familiarity-based responses dominate (i.e., prior to about $600 \mathrm{msec}$ of total processing time [signal lag + response time]; Dosher, 1984; Hintzman \& Curran, 1994). If a recall-to-reject process is used, those errors will decrease at longer response-signal lags, and more so than for the unrelated novel lures, since recollection of the studied word allows specific rejection of the related lure (e.g., Hintzman \& Curran, 1994; Rotello \& Heit, 1999). In contrast, in Experiment 1, the lexemes of studied opaque compounds apparently did not feel familiar, so we predicted that opaque disassembly errors would be minimal at all signal lags. It was possible, however, that there would be more complex changes in responding over time. To maximize the efficacy of recall-to-reject, we presented study items three times each (Jones, 2005; Jones \& Jacoby, 2001); in a similar response-signal study, Jones et al. (2007, Experiment 3) failed to find evidence for recall-to-reject when items were studied only once.

Ideally, response-signal experiments map out the full time course of the underlying memory processes for individual participants, using many trials of each stimulus type at each signal lag. Given our limited materials, we used a between-subjects design (see also Jones et al., 2007) and a set of response-signal lags intended to capture the growth of the familiarity-based responses (i.e., lags up to $450 \mathrm{msec}$, yielding total processing times that were about $600 \mathrm{msec})$, as well as a long lag $(2,000 \mathrm{msec})$ intended to capture the full contribution of recall-to-reject processing.

\section{Method}

Participants. Ninety-two University of Massachusetts undergraduates participated for cash or extra credit in their psychology courses. All of the participants were native English speakers; none had participated in the earlier experiments.

Stimuli and Design. The stimulus structure for Experiment 2 is shown in Table 3, along with example stimuli of each type. Sixty compound words and 100 fillers were used (see the Appendix). Half of the compound words were opaque (mean transparency $=2.35$, $S D=0.70$ ); half were transparent (mean transparency $=6.05, S D=$ 0.39 ). For each participant, 10 opaque and 10 transparent compound words were selected for study; these items appeared as compound targets on the recognition test. Twenty additional compound words (half opaque) served as compound lures on the test. The participants also studied 30 long and 30 short filler words (randomly chosen from the stimulus set for each participant); 20 of each type were selected to be filler targets on the recognition test. Twenty long and 20 short additional filler words served as filler lures. The long fillers were most similar to the compound words in mean length $(M=$ 8.2 letters vs. $M \mathrm{~s}=8.6$ and 8.9 for opaque and transparent compounds, respectively) and number of syllables $(M=2.9$ vs. $M \mathrm{~s}=$ 2.1 and 2.1); and short fillers were most similar to the disassembly lures in mean length $(M=4.2$ letters vs. $M \mathrm{~s}=4.6$ and 4.3 for lexemes with opaque and transparent parents, respectively) and number of syllables ( $M=1.0 \mathrm{vs} . M \mathrm{~s}=1.1$ and 1.2 for lexemes with opaque and transparent parents, respectively).

Finally, each participant studied 20 critical compound words that were broken into their component lexemes on the recognition test (disassembly lures). These critical compounds were carefully matched on a number of relevant dimensions, so all of the participants studied the same 20 critical compounds and were tested on the same 40 disassembly lures. The critical compounds were matched on familiarity (opaque, $M=6.14$; transparent, $M=6.22$ ) and concreteness (opaque, $M=5.92$; transparent, $M=5.97$ ), but differed in semantic transparency (opaque, $M=2.72$; transparent, $M=6.22$ ). In addition, these compounds' lexemes matched closely on mean linguistic frequency (opaque, $M=65.4$; transparent, $M=59.1$ ), word length (opaque, $M=4.6$ letters; transparent, $M=4.3$ letters), and number of syllables (opaque, $M=1.1$; transparent, $M=1.2$ ).

In all, the study list consisted of three blocks of 100 unique words: The 40 compound words (half opaque) and 60 fillers (30 long, 30 short) appeared once in each block. The study order within each block was randomized for each participant. Four additional words were used as primacy and recency items.

The test list consisted of 160 items. Sixty test probes were targets (20 long and 20 short fillers, 10 transparent and 10 opaque compounds), 60 were completely new lures (20 long and 20 short fillers, 10 transparent and 10 opaque compounds), and the remaining 40 test probes were disassembly lures (half from opaque parents). The test order was randomized for each participant, except that the first 16 test trials were always fillers.

There were six response-signal conditions: $150 \mathrm{msec}(n=14)$, $200 \mathrm{msec}(n=16), 250 \mathrm{msec}(n=15), 325 \mathrm{msec}(n=18), 450 \mathrm{msec}$ $(n=14)$, and 2,000 $\mathrm{msec}(n=15)$; the participants were randomly assigned to these conditions.

Procedure. All of the participants started with a 30-item training block on the response-signal procedure. Each training trial began with a fixation cross ("+") presented in the middle of the screen. Then a practice word ("yes" or "no") appeared on the screen for 150 , $200,250,325,450$, or $2,000 \mathrm{msec}$, depending on the response-signal condition. Next, a visual mask appeared (“*******”) simultaneous with an auditory cue (a computer click) to signal the participant to 
respond. The participants pressed the "/" button if the practice word was "yes" (meaning that it had been studied) and the " $z$ " button if the word was "no" (new); they were told to respond within $350 \mathrm{msec}$ of the click. If they responded prior to the signal, the response was ignored; if they responded more than $350 \mathrm{msec}$ after the signal, warning feedback ("Too slow!") appeared on the screen for 2,000 msec prior to the next trial. Most of the participants responded within the desired time window after about 10 practice trials. The participants repeated the training block if they missed the window on more than half of the training trials.

In the study phase, the participants were shown a list of 304 study items: two primacy words, two recency words, and three contiguous blocks of the 100 unique study items, each in a different random order. Each word was shown in the middle of the screen for $1,500 \mathrm{msec}$, with a $1,000-\mathrm{msec}$ interstimulus interval. The participants were told that each word would be presented three times and that they would be tested on their memory for the words using a speeded recognition test like they had practiced in the training block. Immediately following the study list, the participants took a 160 -item recognition test using the same response-signal procedure as in the training block. The participants were asked to decide whether each test probe had appeared on the study list and to respond within $350 \mathrm{msec}$ of the signal. Feedback was provided for responses that were too slow, and those responses were not recorded.

\section{Results}

Missing data, from slow responses, constituted $12.8 \%$, $14.8 \%, 8.1 \%, 10.5 \%, 9.0 \%$, and $6.1 \%$ of trials over the lag conditions. These proportions are similar to those in related experiments (Rotello \& Heit, 1999).

The probability of an old judgment to compound words and long fillers is shown in Figure 1A as a function of response signal lag. Targets elicited more old judgments than did lures $\left[F(1,86)=474.99, M S_{\mathrm{e}}=.06, p<.001\right.$, $f=2.35]$, and the false alarm rate to lures showed a bigger effect of response-signal lags than did the hit rate $\left[F(2,172)=8.09, M S_{\mathrm{e}}=.017, p<.001, f=0.31\right]$. Item type (opaque, transparent, or filler) also interacted with old-new status and response-signal lag $[F(10,172)=$ $\left.2.06, M S_{\mathrm{e}}=.017, p<.05, f=0.35\right]$ : Responses to both old and new fillers were relatively unaffected by processing time, but hit rates to compound targets increased over time and false alarm rates decreased.

The critical data are the responses to the disassembly lures, which are most comparable to the short filler lures. The probability of an old judgment to these lures is shown in Figure 1B as a function of response-signal lag. Overall, the error rates differed with the type of lure $\left[F(2,172)=76.507, M S_{\mathrm{e}}=.013, p<.001, f=0.94\right]$ but not with response-signal lag $\left[F(5,86)=1.57, M S_{\mathrm{e}}=\right.$ $.077, f=0.30]$; response-signal lag did not interact with item type. Bonferroni-corrected post hoc comparisons revealed that disassembly lures with transparent parents elicited a significantly higher false alarm rate than did those with opaque parents $[t(91)=7.64, p<.001, d=$ $.80]$, which in turn received more old responses than did short filler lures $[t(91)=4.74, p<.001, d=.49]$. There is no evidence that the false alarm rate to disassembly lures decreased over response-signal lag at a faster rate than that to short filler lures; therefore, there is no evidence for the use of a recall-to-reject process for these lures (Rotello \& Heit, 1999). ${ }^{3}$
A

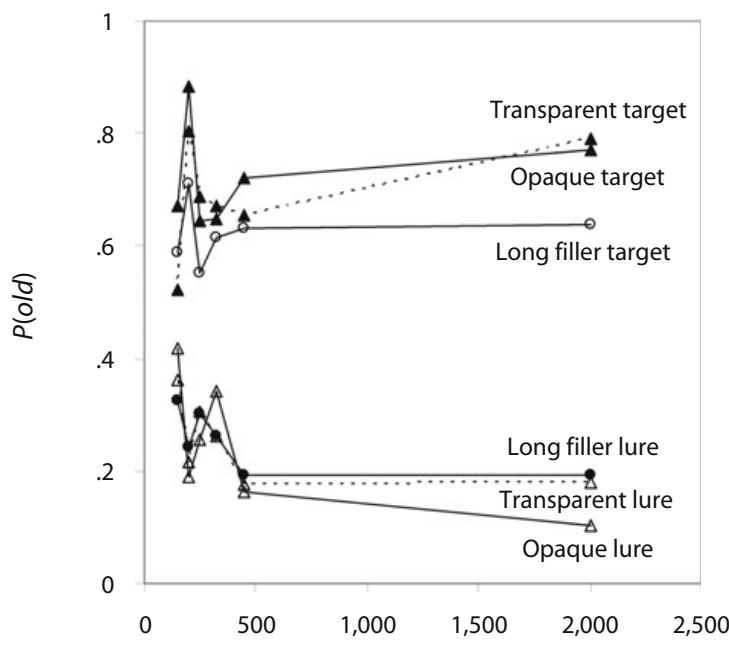

Response-Signal Lag (msec)

B

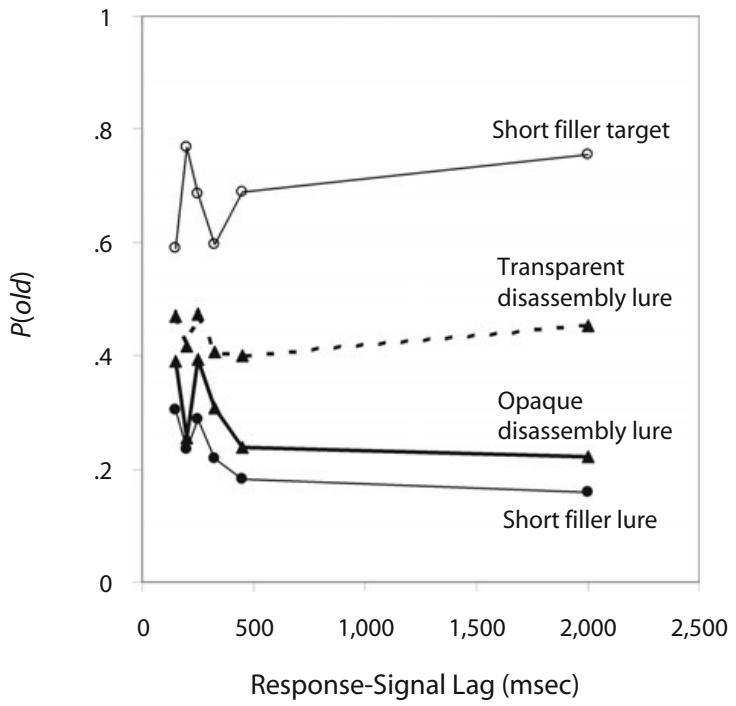

Figure 1. Probability of an old response to test probes in Experiment 2 as a function of response-signal lag. (A) Compound words and long fillers. (B) Short fillers and disassembly lures.

\section{Discussion}

Experiment 2 replicated Experiment 1 in showing a higher false alarm rate for lures that were semantically related to their parents (transparent compounds). There was no evidence for the use of recall-to-reject processing for either type of disassembly lure, which replicates Jones et al.'s (2007, Experiment 3) single-presentation results with multiple study repetitions. Thus, the lack of recall-to-reject processing with conjunction lures is prob- 
ably not attributable to the weak retrieval cue provided by a conjunction lure to the parent compounds. Lures with transparent parents are semantically related to, and presumably good retrieval cues for, those parents, yet no recall-to-reject processing was observed. Because there were no reliable effects of signal lag on the error rates to short filler or disassembly lures, there was also no clear evidence for complex trade-offs of familiarity and recollection as a function of processing time.

The lack of evidence for the use of a recall-to-reject process is somewhat surprising in light of previous data on the probability of recalling a studied parent when faced with a test lure: Participants are sometimes more likely to correctly reject a conjunction or feature lure if they can report at least one of the parent words from which the lure was created (Lampinen et al., 2004). In other studies, however, it has been found that the encoding task affects the probability of recalling a parent word (deeper encoding leads to better recall) without decreasing the associated conjunction error rates (Arndt \& Jones, 2008; Jones et al., 2007, Experiment 1, reported an analogous finding in a recognition task). Our data suggest a similar disconnect between recall rates and error rates: Transparent parents should be easier to recall than opaque parents, because they share with their lexemes both semantic and orthographic/phonemic features, yet the error rates provide no evidence that such recall changes the memory judgments. The false alarm rates decreased with additional processing time (i.e., at the longer response-signal lag), but the rate of decline did not vary across lure types. There is no evidence that the participants used a recall-toreject process to facilitate rejection of disassembly lures with transparent or opaque parents, even though the parent compounds were studied multiple times.

One might argue that by mixing compound words and singletons, we have discouraged the use of recall-to-reject processing, because recall-to-reject would only help the participants on a fraction of the trials (see Rotello et al., 2000 , for a similar argument comparing response-signal and ROC evidence on recall-to-reject). Moreover, we did not explicitly instruct the participants to use a recallto-reject process; such instructions have been shown to increase the evidence for recollection (Rotello et al., 2000). Future experimenters could certainly explore the consequence of those design choices on the use of recallto-reject processing. A possible outcome of those experiments is that the false alarm rate to the disassembly lures with transparent parents may be reduced as recall-to-reject processing is increased. Such a finding would not detract from our primary result, of course, which is that semantic transparency affected familiarity-based processes and dramatically increased the false alarm rate.

\section{GENERAL DISCUSSION}

Opaque compound words contain lexemes that are unrelated to the compound, whereas the lexemes of transparent compound words give rise to the meaning of the compound. Memory was similar for studied and novel compounds of these two stimulus types. However, trans- parent and opaque stimuli have different consequences for judgments of semantically related lures. Transparent compounds and their lexemes share more semantic features than opaque compounds and their lexemes, which apparently leads to greater subjective familiarity of the lexemes of transparent compounds. Thus, the error rates to semantically related lures (i.e., assembly or disassembly lures) increased with the degree of semantic transparency. Transparency has not been controlled in previous studies of memory conjunction errors and may explain some of the variability in the feature error rates that has been observed (Jones \& Jacoby, 2001).

The observation that episodic memory is highly constrained by semantic information has been consistently observed in the false memory literature (e.g., Roediger \& McDermott, 1995). However, little research has been conducted to distinguish among types of semantic relations and their effects on episodic memory. In the memory conjunction paradigm, there are at least three types of semantic relations to consider: (1) parent-parent, (2) parentconjunction lure, and (3) parent-lexeme. Each of these relationships has been shown to affect the observed error rates. Hannigan and Reinitz (2003) found that conjunction lures made from two similar parents yielded higher false alarm rates than those created from dissimilar parents. Odegard et al. (2005) and Leding et al. (2007) found that higher semantic overlap between the parents and their conjunction lures resulted in fewer errors to those lures. Finally, the present experiments revealed that the false alarm rate to semantically related lexemes is higher than to semantically unrelated lexemes. In other words, the individual components of transparent compounds appear to elicit a greater sense of familiarity than do the components of opaque compound words. The semantic relationship between the parents and the lexemes also affects the error rates to assembly lures created from those lexemes. In contrast to the conclusion drawn by Jones et al. (2007), who did not manipulate semantic transparency, our data indicate that conceptual overlap strongly influences the error rates to both assembly and disassembly lures.

The familiarity-based account of conjunction errors (e.g., Jones, 2005) requires some elaboration to fully account for our data. It is not sufficient to consider the number of items to which a test probe is similar, which was equated for our transparent and opaque compounds. Rather, the familiarity of a given lure depends on the semantic relationship of that lure to its parent(s). Our experiments cannot distinguish whether that semantic relationship has its effect during encoding (via spreading activation, as in the source of activation confusion model; Reder, Park, \& Kieffaber, 2009), during retrieval (via a similarity-based calculation of familiarity, as in the global matching models; see Clark \& Gronlund, 1996, for a review), or both. We can rule out one retrieval-based process, however: These data join others in failing to provide evidence for the use of a recall-to-reject process in judgments of semantically related lures. The failure of our participants to use recall-to-reject processing is noteworthy, given that our experimental conditions encouraged recall-to-reject processing (multiple repetitions of studied items, lures that provided potentially strong re- 
trieval cues to the transparent compounds). Although the study list was quite long in Experiment 2, which tends to reduce recall-to-reject processing, the number of unique items was similar to that in previous studies. Moreover, the study list was substantially shorter in Experiment 1, yet no evidence for recall-to-reject was observed in that study either.

The present data suggest that compound words are represented differently in episodic memory depending on their transparency. Some lexemes appear to be highly activated in memory, whereas others are relatively inaccessible. These differences do not influence memory recognition for the compound, but they greatly affect the likelihood of conjunction and disassembly errors.

\section{AUTHOR NOTE}

This research was supported by Grant MH60274 from the National Institutes of Health to C.M.R. and was conducted as part of M.W.'s dissertation. We thank Todd Jones, Colleen Kelley, Timothy Odegard, and two anonymous reviewers for their comments on this work. Correspondence concerning this article should be addressed to C. M. Rotello, Department of Psychology, Box 37710, University of Massachusetts, Amherst, MA 01003-7710 (e-mail: caren@psych.umass.edu).

\section{REFERENCES}

ARndT, J., \& Jones, T. C. (2008). Elaborative processing and conjunction errors in recognition memory. Memory \& Cognition, 36, 899-912.

Clark, S. E., \& Gronlund, S. D. (1996). Global matching models of recognition memory: How the models match the data. Psychonomic Bulletin \& Review, 3, 37-60.

DosHER, B. A. (1984). Discriminating preexperimental (semantic) from learned (episodic) associations: A speed-accuracy study. Cognitive Psychology, 16, 519-555. doi:10.1016/0010-0285(84)90019-7

Ghatala, E. S., Levin, J. R., Bell, J. A., Truman, D. L., \& Lodico, M. G. (1978). The effect of semantic and nonsemantic factors on the integration of verbal units in recognition memory. Journal of Experimental Psychology: Human Learning \& Memory, 4, 647-655. doi:10.1037/0278-7393.4.6.647

Glanzer, M., \& Adams, J. K. (1990). The mirror effect in recognition memory: Data and theory. Journal of Experimental Psychology: Learning, Memory, \& Cognition, 16, 5-16. doi:10.1037/0278-7393.16.1.5

Hannigan, S. L., \& Reinitz, M. T. (2003). Migration of objects and inferences across episodes. Memory \& Cognition, 31, 434-444.

Hintzman, D. L., \& Curran, T. (1994). Retrieval dynamics of recognition and frequency judgments: Evidence for separate processes of familiarity and recall. Journal of Memory \& Language, 33, 1-18. doi:10.1006/jmla.1994.1001

Jarema, G., Busson, C., Niklova, R., Tsapkini, K., \& Libben, G. (1999). Processing compounds: A cross-linguistic study. Brain \& Language, 68, 362-369. doi:10.1006/brln.1999.2088

JoNES, T. C. (2005). Study repetition and the rejection of conjunction lures. Memory, 13, 499-515. doi:10.1080/09658210444000197

Jones, T. C., \& ATCHLEY, P. (2002). Conjunction error rates on a continuous recognition memory test: Little evidence for recollection. Journal of Experimental Psychology: Learning, Memory, \& Cognition, 28, 374-379. doi:10.1037/0278-7393.28.2.374

Jones, T. C., \& ATchley, P. (2006). Conjunction errors, recollectionbased rejections, and forgetting in a continuous recognition task. Journal of Experimental Psychology: Learning, Memory, \& Cognition, 32, 70-78. doi: 10.1037/0278-7393.32.1.70

Jones, T. C., Brown, A. S., \& AtChley, P. (2007). Feature and conjunc- tion effects in recognition memory: Toward specifying familiarity for compound words. Memory \& Cognition, 35, 984-998.

JONES, T. C., \& JACOBY, L. L. (2001). Feature and conjunction errors in recognition memory: Evidence for dual-process theory. Journal of Memory \& Language, 45, 82-102. doi:10.1006/jmla.2000.2761

Juhasz, B. J., Stark, M. S., Inhoff, A. W., \& Placke, L. (2003). The effects of morphology on the processing of compound words: Evidence from naming, lexical decisions and eye fixations. British Journal of Psychology, 94, 223-244. doi:10.1348/000712603321661903

KUČERA, H., \& FRANCIS, W. N. (1967). Computational analysis of presentday American English. Providence, RI: Brown University Press.

Lampinen, J. M., Odegard, T. N., \& Neuschatz, J. S. (2004). Robust recollection rejection in the memory conjunction paradigm. Journal of Experimental Psychology: Learning, Memory, \& Cognition, 30, 332-342. doi:10.1037/0278-7393.30.2.332

Leding, J. K., Lampinen, J. M., Edwards, N. W., \& Odegard, T. N. (2007). The memory conjunction error paradigm: Normative data for conjunction triplets. Behavior Research Methods, 39, 920-925.

Libben, G., Gibson, M., Yoon, Y. B., \& Sandra, D. (2003). Compound fracture: The role of semantic transparency and morphological headedness. Brain \& Language, 84, 50-64. doi:10.1016/S0093 $-934 X(02) 00520-5$

Odegard, T. N., LAMPinen, J. M., \& Toglia, M. P. (2005). Meaning's moderating effect on recollection rejection. Journal of Memory \& Language, 53, 416-429. doi:10.1016/j.jml.2005.04.004

Reder, L. M., Park, H., \& Kieffaber, P. D. (2009). Memory systems do not divide on consciousness: Reinterpreting memory in terms of activation and binding. Psychological Bulletin, 135, 23-49. doi:10.1037/ a0013974

Roediger, H. L., III, \& McDermott, K. B. (1995). Creating false memories: Remembering words not presented in lists. Journal of Experimental Psychology: Learning, Memory, \& Cognition, 21, 803-814. doi: $10.1037 / 0278-7393.21 .4 .803$

Rotello, C. M., \& Heit, E. (1999). Two-process models of recognition memory: Evidence for recall-to-reject? Journal of Memory \& Language, 40, 432-453. doi:10.1006/jmla.1998.2623

Rotello, C. M., \& Heit, E. (2000). Associative recognition: A case of recall-to-reject processing. Memory \& Cognition, 28, 907-922.

Rotello, C. M., Macmillan, N. A., \& Van Tassel, G. (2000). Recall-to-reject in recognition: Evidence from ROC curves. Journal of Memory \& Language, 43, 67-88. doi:10.1006/jmla.1999.2701

WiXted, J. T. (1992). Subjective memorability and the mirror effect. Journal of Experimental Psychology: Learning, Memory, \& Cognition, 18, 681-690. doi:10.1037/0278-7393.18.4.681

Yonelinas, A. P. (2002). The nature of recollection and familiarity: A review of 30 years of research. Journal of Memory \& Language, 46, 441-517. doi:10.1006/jmla.2002.2864

\section{NOTES}

1. This excludes one outlier, time, with a very high frequency. We reached the same statistical conclusion when that item was included in the analysis $(p>.1)$.

2. In English, the morphological head of compound words is typically the second lexical morpheme (Libben, Gibson, Yoon, \& Sandra, 2003). Lexical decision times are faster when the target is primed by its morphological head rather than by a nonhead constituent, suggesting that the morphological headedness influences the processing of compound words (e.g., Jarema et al., 1999). No dependent measure in this study was influenced by morphological headedness.

3. Rotello and Heit $(1999,2000)$ emphasized the importance of estimating changes in memory accuracy as a function of processing time, because of the potential for changes in response bias across response signal lags. In this experiment, such an analysis is not necessary, since the false alarm rates to short fillers (the control items for the disassembly lures) did not vary with response-signal lag. 
APPENDIX

Stimulus Sets in Each Experiment

Table A1

Stimulus Set in Experiment 1

\begin{tabular}{|c|c|c|}
\hline Opaque Compounds & Transparent Compounds & Fillers (Short and Long) \\
\hline beeline & barbershop & beer \\
\hline blackmail & bathrobe & brush \\
\hline blockhead & battlefield & cake \\
\hline brainwash & bedroom & cathedral \\
\hline breakfast & bloodstain & chocolate \\
\hline broadcast & bookshelf & clock \\
\hline buttercup & boyfriend & corridor \\
\hline catwalk & buttonhole & election \\
\hline cheapskate & candlewax & envelope \\
\hline dashboard & cheekbone & fork \\
\hline dragonfly & clamshell & grass \\
\hline dumbbell & crossroad & hospital \\
\hline fanfare & doorknob & invention \\
\hline greenhorn & drainpipe & invitation \\
\hline hallmark & fingertip & magazine \\
\hline hamstring & fireplace & mechanic \\
\hline hardware & flagpole & medicine \\
\hline highlight & grapevine & monument \\
\hline homesick & graveyard & newspaper \\
\hline jailbird & hailstorm & orchestra \\
\hline killjoy & haircut & politician \\
\hline kingpin & heartbeat & principal \\
\hline ladybug & inkpot & prisoner \\
\hline longhand & lampshade & professor \\
\hline mainstay & lifeguard & propeller \\
\hline mothball & nosebleed & restaurant \\
\hline peppermint & nutcracker & ring \\
\hline pineapple & playground & secretary \\
\hline potluck & pushcart & sink \\
\hline ragtime & seafood & slow \\
\hline scapegoat & shoelace & smoke \\
\hline shortbread & sketchpad & sock \\
\hline showcase & snakeskin & thick \\
\hline sidekick & soupspoon & triangle \\
\hline slapstick & tablecloth & \\
\hline strawberry & teardrop & \\
\hline tightwad & thumbnail & \\
\hline toadstool & toothpick & \\
\hline treadmill & wastebasket & \\
\hline wallflower & wheelchair & \\
\hline
\end{tabular}


APPENDIX (Continued)

Table A2

Stimulus Set in Experiment 2

\begin{tabular}{|c|c|c|c|c|c|}
\hline \multicolumn{2}{|c|}{ Compounds } & \multicolumn{4}{|c|}{ Fillers } \\
\hline Opaque & Transparent & Lo & & & ort \\
\hline $\begin{array}{l}\text { bankroll } \\
\text { beeline } \\
\text { blackmail } \\
\text { blockhead } \\
\text { brainwash } \\
\text { catwalk } \\
\text { deadline } \\
\text { drawback } \\
\text { greenhorn } \\
\text { hallmark } \\
\text { highlight } \\
\text { mushroom } \\
\text { potluck } \\
\text { scapegoat } \\
\text { shortbread } \\
\text { slapstick } \\
\text { strawberry } \\
\text { tightwad } \\
\text { turnpike } \\
\text { wallflower }\end{array}$ & $\begin{array}{l}\text { bloodstain } \\
\text { bookshelf } \\
\text { shoelace } \\
\text { clamshell } \\
\text { earache } \\
\text { fingertip } \\
\text { fireplace } \\
\text { flagpole } \\
\text { grapevine } \\
\text { hailstorm } \\
\text { handbag } \\
\text { heartbeat } \\
\text { nosebleed } \\
\text { nutcracker } \\
\text { seafood } \\
\text { snowball } \\
\text { teardrop } \\
\text { toothpick } \\
\text { watchdog } \\
\text { wheelchair }\end{array}$ & $\begin{array}{l}\text { alcohol } \\
\text { alphabet } \\
\text { article } \\
\text { avalanche } \\
\text { cabinet } \\
\text { cathedral } \\
\text { chocolate } \\
\text { cigarette } \\
\text { citizen } \\
\text { corridor } \\
\text { department } \\
\text { diamond } \\
\text { election } \\
\text { envelope } \\
\text { gallery } \\
\text { hospital } \\
\text { invention } \\
\text { invitation } \\
\text { janitor } \\
\text { limousine } \\
\text { magazine } \\
\text { mechanic } \\
\text { medicine } \\
\text { mineral } \\
\text { monument }\end{array}$ & $\begin{array}{l}\text { squirrel } \\
\text { orchestra } \\
\text { politician } \\
\text { principal } \\
\text { prisoner } \\
\text { professor } \\
\text { propeller } \\
\text { restaurant } \\
\text { secretary } \\
\text { syllable } \\
\text { telephone } \\
\text { triangle } \\
\text { umbrella } \\
\text { vegetable } \\
\text { vinegar } \\
\text { audience } \\
\text { contract } \\
\text { mountain } \\
\text { dandelion } \\
\text { tourist } \\
\text { journal } \\
\text { century } \\
\text { mosquito } \\
\text { holiday } \\
\text { cardinal }\end{array}$ & $\begin{array}{l}\text { beer } \\
\text { milk } \\
\text { brick } \\
\text { cage } \\
\text { couch } \\
\text { debt } \\
\text { doll } \\
\text { foam } \\
\text { house } \\
\text { hook } \\
\text { judge } \\
\text { loop } \\
\text { rust } \\
\text { seal } \\
\text { sink } \\
\text { stew } \\
\text { sword } \\
\text { tent } \\
\text { wine } \\
\text { wool } \\
\text { clock } \\
\text { brush } \\
\text { cake } \\
\text { fork } \\
\text { grass }\end{array}$ & $\begin{array}{l}\text { wood } \\
\text { thick } \\
\text { ring } \\
\text { sock } \\
\text { duck } \\
\text { leaf } \\
\text { tea } \\
\text { fan } \\
\text { fare } \\
\text { leap } \\
\text { frog } \\
\text { long } \\
\text { hand } \\
\text { step } \\
\text { stay } \\
\text { bath } \\
\text { post } \\
\text { play } \\
\text { wind } \\
\text { point } \\
\text { thumb } \\
\text { nail } \\
\text { stone } \\
\text { oil } \\
\text { key }\end{array}$ \\
\hline
\end{tabular}

Table A3

Critical Items From Which the

Disassembly Lures Were Created

\begin{tabular}{ll}
\hline Opaque & Transparent \\
\hline breakfast & battlefield \\
buttercup & buttonhole \\
dashboard & cheekbone \\
dragonfly & doossroad \\
dumbbell & drainpipe \\
hamstring & graveyard \\
ladybug & lampshade \\
pineapple & snakeskin \\
sidekick & soupspoon \\
treadmill & \\
\hline
\end{tabular}

(Manuscript received April 9, 2009;

revision accepted for publication June 25,2009 .) 